International

Medical Society

http://imedicalsociety.org
International Archives of Medicine

Section: Cardiology

ISSN: 1755-7682

\section{Serum Aldosterone Levels in Hypertension}

Mariana Jancis Rigolo', Adriano Meneghini ${ }^{1}$, Neif Murad'1, Antonio Carlos Palandri Chagas ${ }^{1}$, Marcelo Rodrigues Bacci1,2, Fernando Luiz Affonso Fonseca ${ }^{2}$

\section{Abstract}

Aims: Hypertension affects around $30 \%$ of the adult population. It is related to cardiovascular complications, especially on account of atherosclerosis. Resistant hypertension $(\mathrm{RH})$ occurs when blood pressure remains above target value despite the use of three antihypertensive medications with synergistic actions at maximum recommended doses or whenever the patient makes use of four or more antihypertensive drugs even when blood pressure is controlled. Hyperaldosteronism is an important cause of $\mathrm{RH}$. The study aims to evaluate the association of aldosterone concentrations not only in essential hypertensive individuals but with $\mathrm{RH}$ correlating also with inflammatory levels.

Methods: A total of $44 \mathrm{EH}$ patients and $32 \mathrm{RH}$ patients were selected. All of them were submitted to serum analysis of urea, creatinine, potassium, aldosterone, fasting glycemia, glycated hemoglobin ( $\mathrm{HbA1C})$, complete blood count, usCRP, homocysteine and beta-2 microglobulin (B2M).

Results: No significant difference could be observed among the groups regarding the inflammatory markers TNF-alpha, IL-6, usCRP, homocysteine and B2M. As to aldosterone and the ratio of albumin to creatinine $(A C R)$, there was an expressive difference; however, no correlation between ACR and aldosterone could be found.

Conclusions: In this sample of hypertensive individuals, aldosterone levels are relatively higher in $\mathrm{RH}$ when compared with those with $\mathrm{EH}$.

\section{Introduction}

Arterial hypertension (AH) affects around 30\% of the adult population. In Brazil, populational studies carried out between 1994 and 2009 showed low levels of blood pressure control (19.6\%). Framingham re-
1 Department of Cardiology of Faculdade de Medicina do ABC- Santo André, Brazil.

2 Department of General Practice of Faculdade de Medicina do ABC- Santo André, Brazil.

\section{Contact information:}

\section{Marcelo Rodrigues Bacci}

Address: Av. Principe de Gales n 821Santo André- ZIP: 09060-650. Santo André, São Paulo, Brazil. Tel: +55 11981937005 .

झmrbacci@yahoo.com

\section{Keywords}

Aldosterone; Resistant Hypertension; Arterial Hypertension. 
vealed that the range of blood pressure values defined as pre-hypertension (130-139 mmHg X 85-89 $\mathrm{mmHg}$ ) is associated with 1.6- to 2.5 -fold higher risk of cardiovascular diseases. The exact prevalence of resistant hypertension $(\mathrm{RH})$ is not established, but it is estimated that it affects around $12-15 \%$ of hypertensive patients [1]. Data analysis from the National Health and Nutrition Examination Survey (NHANES) 2003-2008 showed that $12.8 \%$ of hypertensives in use of antihypertensives were identified as $\mathrm{RH}$ individuals.

The disease prognosis is related to factors like long-term hypertension, damages in target organs, mineralocorticoid excess (aldosterone) and high sodium intake. Some important studies like RALES and EPHESUS, which tested the use of aldosterone receptor blockers in the treatment of heart failure and myocardial disorders, highlighted the fact that aldosterone contributes to target organ lesion due to cell alterations and pointed it out as an important marker for cardiovascular mortality [2].

Concerning the inflammatory markers beta- 2 microglobulin [4] and homocysteine [5], there are not enough studies that correlate these markers with aldosterone and resistant hypertension; nevertheless, it is a known fact that they are both present in patients with cardiovascular risk. Beta-2 microglobulin is a low molecular weight protein associated with class I major histocompatibility complex (MHC-I) proteins. It is present in all nucleated cells, especially in lymphocytes. Due to its low molecular weight, it can cross the glomerular membrane and be reabsorbed by the proximal tubules. An increase in its serum levels is related to the increase in cellular renewal, and it may be present in diseases like chronic inflammation, kidney disorders, leukemias and lymphomas [8]. Homocysteine is a nonessential amino acid derived from the methionine metabolism. Hyperhomocysteinemia is a risk factor independent from cardiovascular diseases, and it can also be related to the onset of neurological conditions [9].
The aim of this study is to evaluate aldosterone serum levels in essential and resistant hypertensive patients.

\section{Methods}

\section{Study Design and Patient Screening Process}

This is a cross-sectional study with hypertensive patients who were being followed up at the Faculdade de Medicina do ABC. The trial was approved by the local ethics committee, which strictly followed the principles expressed in the Declaration of Helsinki.

Hypertensive patients were included. Resistant subjects were those who were being treated with at least three antihypertensives of different classes (one of them a thiazide diuretic) in optimal doses according to the guidelines of the Brazilian Society of Cardiology.

Exclusion criteria comprised the following issues: patients who had been hospitalized, for no matter what reason, within 30 days prior to the beginning of the study; those who were on aldosterone antagonists; individuals with an active infection profile; human immunodeficiency virus carriers with hepatitis B and/or C; patients with terminal chronic kidney disease (CKD) on dialysis, or those with stage 4 or 5 CKD under conservative treatment (Modification of Diet in Renal Diseases simplified formula [7] (MDRD) was used to estimate glomerular filtration rate(eGFR); patients with neoplasia of any kind.

\section{Analyzed variables}

Blood pressure levels were measured during patients' visits. Laboratory evaluation included the determination of serum levels of creatinine, aldosterone, glycated hemoglobin, ultrasensitive C-reactive protein, homocysteine, interleukin-6, beta-2 microglobulin, alpha tumor necrosis factor and urine albumin-creatinine ratio (ACR) from the first morning urine sample. 


\section{Statistical Analysis}

At first all the variables were descriptively analyzed. For quantitative variables, the analysis was made through the observation of minimum and maximum values as well as the calculation of means, standard deviations and medians. For qualitative variables, absolute and relative frequencies were calculated.

In order to compare the means between paired groups, the Student's t-test was used; whenever the normality supposition was not met, the nonparametric Mann-Whitney test was carried out.

The chi-square test was performed to evaluate the homogeneity between proportions; the Fisher's exact test was applied when expected frequencies of less than 5 occurred. Significance level for the tests was set at $5 \%$. Stata 12 was the statistical package of choice.

\section{Results}

Table 1 shows the demographic parameters of the studied population. The predominance of white and obese patients with high glycemic levels in both groups can be observed. It is important to point out that there was no significant difference between the profile of essential and resistant hypertensives. In other words, no significant variations concerning ethnicity, age or gender between both groups were found, thus dissociating resistance from pre-established factors like black race and female gender in this study.

Table 2 compares the biochemical and laboratory parameters between essential and resistant hypertensives.

\section{Inflammatory Markers}

The fact that there was no significant difference between groups regarding the inflammatory markers TNF-alpha, IL-6, usCRP and homocysteine suggests that although resistant hypertensives are more likely to have typical inflammatory diseases
Table 1. Clinical and demographic characteristics of groups.

\begin{tabular}{|l|c|c|c|}
\multicolumn{1}{|c|}{ Variables } & $\begin{array}{c}\text { Resistant } \\
\text { Hypertensives } \\
(\mathbf{N}=\mathbf{3 2})\end{array}$ & $\begin{array}{c}\text { Essential } \\
\text { Hypertensives } \\
(\mathbf{N}=\mathbf{4 4})\end{array}$ & $\mathbf{p}$ \\
\hline Age (years) (\%) & 63.68 & 61.70 & $0.38^{\mathrm{A}}$ \\
\hline $\begin{array}{l}\text { Gender (men) (\%) } \\
\text { Ethnicity }\end{array}$ & 58.62 & 52.27 & $0.20^{\mathrm{B}}$ \\
\hline (Caucasians) (\%) & 68.96 & 79.54 & $0.30^{\mathrm{B}}$ \\
\hline BMl & 30.1 & 31.2 & $0.24^{\mathrm{A}}$ \\
\hline Smoking (\%) & 6.98 & 9.1 & $1^{\mathrm{C}}$ \\
\hline AMI (\%) & 13.79 & 13.63 & $1^{\mathrm{C}}$ \\
\hline Stroke (\%) & 3.44 & 0 & $0.38^{\mathrm{C}}$ \\
\hline CABG (\%) & 3.44 & 6.81 & ${ }_{1}^{\mathrm{C}}$ \\
\hline \multicolumn{1}{|c|}{ A: Student's t-test, $\mathrm{B}$ : Chi-square test, $\mathrm{C}$ : Fisher's exact test. } \\
\hline
\end{tabular}

Table 2. Comparison of metabolic and inflammatory markers between essential and resistant hypertensives.

\begin{tabular}{|c|c|c|c|}
\hline Variables & $\begin{array}{l}\text { Resistant } \\
\text { Hypertensives } \\
\quad(\mathrm{N}=32)\end{array}$ & $\begin{array}{l}\text { Essential } \\
\text { Hypertensives } \\
(\mathrm{N}=44)\end{array}$ & $P * *$ \\
\hline $\begin{array}{l}\text { Creatinine } \\
(\mathrm{mg} / \mathrm{dL})\end{array}$ & 1.26 & 1.19 & 0.19 \\
\hline $\begin{array}{l}\text { GFR } \\
\left(\mathrm{ml} / \mathrm{min} / 1,73 \mathrm{~m}^{2}\right)\end{array}$ & 66.96 & 77.54 & 0.22 \\
\hline HbA1c (\%) & 7.57 & 8.36 & 0.82 \\
\hline TNF (pg/mL) & 9.8 & 10.35 & 0.13 \\
\hline IL-6 (pg/mL) & 2.5 & 2 & 0.29 \\
\hline $\mathrm{B} 2 \mathrm{M}(\mathrm{ng} / \mathrm{mL})$ & 2999.29 & 2673.07 & 0.78 \\
\hline $\begin{array}{l}\text { Homocysteine } \\
\text { (umol/L) }\end{array}$ & 12.21 & 12.67 & 0.24 \\
\hline Aldosterone & 128.76 & 73.7 & 0.01 \\
\hline usCRP (mg/L) & 7.75 & 11.65 & 0.17 \\
\hline ACR $(\mathrm{mg} / \mathrm{g})$ & 189.42 & 77.28 & 0.02 \\
\hline \multicolumn{4}{|c|}{ ** : Non-parametric Mann-Whitney test } \\
\hline \multicolumn{4}{|c|}{$\begin{array}{l}\text { BMI: Body Mass Index / AMI: Acute Myocardial Infarction / CABG } \\
\text { - Coronary artery bypass grafting/ GFR: Glomerular Filtration Rate } \\
\text { / HbA1c: Glycated Hemoglobin / TNF: Tumor Necrosis Factor / IL-6: } \\
\text { Interleukin-6 / B2M: beta-2 microglobulin / usCRP: ultrasensitive } \\
\text { C-Reactive Protein / ACR - Albumin-Creatinine Ratio }\end{array}$} \\
\hline
\end{tabular}


like obesity (BMI=31.2), they did not present a significant increase in inflammatory levels in this analysis.

\section{Aldosterone and Glomerular Filtration Rate}

Concerning aldosterone, according to the non-parametric Mann-Whitney test, the $p$ value found was 0.015 . The resistant hypertensive group had significant higher levels than the essential group. The same observation can be made in regard to ACR levels, with $\mathrm{p}=0.023$.

The eGFR between both groups did not reveal the presence of any clinically significant kidney disease since the values found were higher than 60 $\mathrm{mL} / \mathrm{min} / 1.73 \mathrm{~m}^{2}$.

\section{Discussion}

According to the results here obtained, arterial hypertension is a disease that predominantly occurs in white male individuals with high glycemic levels. It is important to point out that there was no significant difference between the profile of essential and resistant hypertensives. In other words, no significant variations concerning ethnicity, age or gender between both groups were found, thus dissociating resistance from pre-established factors like black race and female gender in this study.

Many mechanisms seem to contribute to the pathogenesis of $\mathrm{RH}$, especially hyperaldosteronism. Regarding aldosterone, a significant difference between essential and resistant hypertensive groups could be seen. The presence of higher levels of aldosterone in the resistant hypertensive group may not only imply an increased cardiovascular risk but also throw light on a differentiated approach in the treatment of these patients.

ACR also had a significant difference, which indicates altered kidney function owing to the increased urinary loss of albumin and result in an even higher risk of coronary diseases once today $A C R$ is con- sidered a marker of cardiovascular risk, especially among black individuals [10]. This significant elevation suggests an increase in incidence of kidney injuries in this population over time.

Today, RH treatment is based on the use of medications associated with changes in the patient's lifestyle, such as a sodium-restricted diet in particular, and the regular practice of physical activities [12]. However, interventions like the percutaneous renal sympathetic denervation, which aims to decrease the adrenergic hyperactivity, frequent in $\mathrm{RH}$ patients, have been studied as an alternative to the treatment. $[13,14]$

Some studies reveal that the use of aldosterone receptor antagonists, like spironolactone and eplerenone, has proved to be unreliable due to the great risk of hyperpotassemia patients are exposed to when on these drugs. On the other hand, studies on drugs that inhibit aldosterone synthase, targeting new therapeutic strategies for treatment, are currently in progress.

Schumacher et al conducted a study that investigated the first generation aldosterone synthase inhibitor. The authors analyzed the use of the drug in different types of hypertension, but the medication demonstrated limitations. Nevertheless, they believe that in the future such drugs may become a complementary tool in the treatment of hypertension. [15]

The PATHWAY-2 study evaluated the additional use of spironolactone in the conventional drug therapy for resistant hypertension. Subjects had been on three different drugs and their blood pressure was measured with an automatic device during the treatment. Around $75 \%$ of the cases showed a clinical improvement when spironolactone was used, suggesting that treatments that induce sodium excretion have proved to be more effective. [16]

In sum, the conclusion is that aldosterone levels are relatively higher in $\mathrm{RH}$ patients when compared with those with essential hypertension. 


\section{Conflict of Interests}

There are no conflict of interests to report in this study.

\section{References}

1. Alessi A, Brandão AA, Coca A, Cordeiro AC, Nogueira Ar, Diógenes de Magalhães $F$, Amodeo C, Saad Rodrigues $\mathrm{Cl}$, Calhoun DA, Barbosa Coelho E, Pimenta E, et al. First Brazilian Position on Resistant Hypertension. Arq Bras Cardiol 2013; 100(3): 304

2. Calhoun DA, Jones D, Textor S, Goff DC, Murphy TP, Toto RD, White A, Cushman WC, White W, Sica D, Ferdinand K, Giles TD, Falkner B, Carey RM; Resistant hypertension: diagnosis, evaluation, and treatment. A scientific statement from the American Heart Association Professional Education Committee of the Council for High Blood Pressure Research. Hypertension. 2008; 51(6):1403-19.

3. Girioli, SU. Hipertensão arterial resistente: Papel da aldosterona e o efeito de seu antagonista espironolactona no remodelamento cardiovascular e função endotelial / Samira Ubaid Girioli. Campinas, SP : [s.n.], 2009.

4. Real de Asúa D, Purchades R, Garcia-Poli I, Suarez C. Beta 2 Microglobulin in High-Vascular- Risk Patientes. Int Cardiovascular Res J. 2012; 6(4).

5. Baszczuk A, Musialik K, Kopczynski J, Thielemann A, Kopczynski Z, Kesy L, Dopierala G. Hyperhomocysteinemia, Lipid and Lipoprotein Disturbances in Patients with Primary Hypertencsion. Advances in Medical Sciences 59 (2014) 68-73.

6. Oliveira-Filho AF, Barreto-Filho JA, Neves SJF, Lyra DPJr Association between the 8-item Morisky Medication Adherence Scale (MMAS-8) and Blood Pressure Control. Bras Cardiol. 2012; 99(1) 649-658

7. Levey AS, Bosch JP, Lewis JB, Greene T, Rogers N, Roth D. A more accurate method to estimate glomerular filtration rate from serum creatinine: A new prediction equation. Modification of Diet in Renal Disease Study Group. Ann Intern Med 1999; 130(6):461-470

8. Peterson PA, Cunningham BA, Berggard I, Edelman GM. Beta 2macroglobulin- a free immunoglobulin domais. Proc Natl Acad Sci USA 1972; 69: 1697-701.

9. Li JJ, Li Q, Du HP, You SJ, Wang Fe, Xu XS, Cheng J, Cao YJ, Liu C, Hu LF. Homocysteine Triggers Inflammatory Responses in Macrophages Through Inhibiting CSE-H2S Signaling via DNA Hypermethylation of CSE Promoter. Int. J. Mol. Sci. 2015, 16, 12560-12577.

10. Gutiérrez OM, Khodneva YA, Muntner P, Rizk DV, McClellan WM, Cushman M, Warnock DG and Safford MM. Association between urinary albumin excretion and coronary heart disease in black versus white adults. JAMA. 2013 Aug 21; 310 (7):10.1001
11. Rigolo MJ, Bacci MR, Murad N, Chagas ACP, Alves BCA, Fonseca FLA. Serum Aldosterone Levels in Hemodialysis Patients: A Systematic Review. Int. Arch. of Medicine. 2015; Vol 8 No.31.

12. Sacks FM, Campos H. Dietary therapy in hypertension. N Engl J Med. 2012: 362(22):2012-12.

13. Krum H, Schlaich M, Whitbourn R, Sobotka PA, Sadowski J, Bartus K, et al. Catheter-based renal sympathetic denervation for resistant hypertension: a multicenter safety and proof-ofprinciple cohort study. Lancet. 2009; 373(9671):1275-81.

14. Esler MD, Krum $H$, Schlaich M, Schmieder RE, Bohm M, Sobotka PA, et al. Renal sympathetic denervation for treatment of drug-resistant hypertension: one year results from the Simplicity HTN-2 randomized, controlled trial. Circulation. 2012:126(25):2976-82.

15. Schumacher CD, Steele RE, Brunner HR. Aldosterone synthase inhibition for the treatment of hypertension and the derived mechanistic requirements dor a new therapeutic strategy.

16. Prevention and Treatment if Hypertension With Algorithmbased therapy (PATHWAY) number 2: protocol for a randomized crossover trial to determine optimal treatment for drug-resistant hypertension.
Publish in International Archives of Medicine

International Archives of Medicine is an open access journal publishing articles encompassing all aspects of medical science and clinical practice. IAM is considered a megajournal with independent sections on all areas of medicine. IAM is a really international journal with authors and board members from all around the world. The journal is widely indexed and classified Q1 in category Medicine. 